\title{
Comparative study on Iran railway and members of international union of railways (UIC)
}

\author{
Razieh Sadat Majidi ${ }^{1}$, Mohammad Mirehei ${ }^{1}{ }^{*}$, Seyed Abbas Ahmadi ${ }^{2}$ \\ ${ }^{1}$ Faculty of Management and Accounting, College of Farabi, University of Tehran, Qom, Iran \\ ${ }^{2}$ Faculty of Geography, University of Tehran, Tehran, Iran
}

\section{A R T I C L E I N F O}

Article history:

Received 2 May 2016

Received in revised form

28 August 2016

Accepted 21 September 2016

Keywords:

Transport

Railways

Iran

UIC

\begin{abstract}
A B S T R A C T
The aim of this research is to indicate the productivity of Iran railway in international transit. This research is conducted using analytical methods based on library studies and documents. In this study, Iran railway and 26 UIC member railways have been studied based on 15 UIC approved indexes (i.e. ten productivity indices as long as five infrastructure Indices). In addition to showing Iran's position in the industry in UIC members, the importance of this industry is examined, especially in Iran and the results show that except two productivity indices (i.e. person kilometers of the passenger coaches and person kilometers to the population), the other indices have performed poorly and need to be studied to strengthen the Iran rail network and fleet.
\end{abstract}

(C) 2016 The Authors. Published by IASE. This is an open access article under the CC BY-NC-ND license (http://creativecommons.org/licenses/by-nc-nd/4.0/).

\section{Introduction}

Transporting is the type of services that its demand depends on other products demand and its supply impresses the supply of most commodities and services significantly. Therefore, it plays a significant role in the GDP. To realize the economic importance of transport, one should consider three important effects of transport on the economic life of humans (i.e. local specialization in production, mass production and expansion of human life). Transport and its development have caused that human increases efficiency of natural resources based on the local specialization in production and its comparative advantages of site locations in promoting mass production. By selecting suitable areas for their lives, in terms of climatic conditions and safety against various risks, human increases the desirability of life.

\section{Problem definition}

The transportation industry as a prerequisite and foundation for development plays a vital role in the reproductive possibilities and potential of communities. It provides the linkage among different elements of development and growth through cargo

\footnotetext{
* Corresponding Author.

Email Address: mirehei@ut.ac.ir (R. Majidi) https://doi.org/10.21833/ijaas.2016.09.011

2313-626X/C) 2016 The Authors. Published by IASE.

This is an open access article under the CC BY-NC-ND license

(http://creativecommons.org/licenses/by-nc-nd/4.0/)
}

and passengers transport. It causes strengthening of various economic, social and cultural parts of countries and plays its role as one of the most important indices in growth and development.

There is a need to transit goods, raw materials, people, ideas and innovations in different parts of the world with varying degrees of course proportional to the level of development of different areas. Transport network with different types and forms, by special arrangement of human is needed in this field. There is also marginal and outlying areas, the extent of variation industrial and manufacturing hub, the center of population and natural mineral resources, regional strategic conditions and many other factors, the importance of communication in the context of development and fertilize the capabilities and features specifies growth in communities.

Transportation and transit of the effects of political, security, social and economic and human civilization owes a large part of it. The geographical situation, access to high seas and fit between landlocked countries, transit in the country has a high potential to direction.

Therefore, Iran has always been due to the strategic position in Asia and has a long way go as the main highway passing through the Far East to the European countries. The Central Asian countries and some East European countries most consumer goods, intermediate and capital need. It also has the ability to export some goods as well. Since the economic and social development depends on access to the high seas through countries without beach 
usually transit routes neighboring countries. So the role of Iran and the rail link is important in this respect.

Due to the importance of transport, especially rail transport role in the development of developed countries, the importance of the fleet in economic exchanges, especially the landlocked countries increases. In this study, we try to position rail fleet in the region and some countries be considered a member of the International Union of railways, Also according to the positioning of the rail crossroads of the world, to develop and strengthen the railway network strategies are proposed.

\section{Theoretical framework}

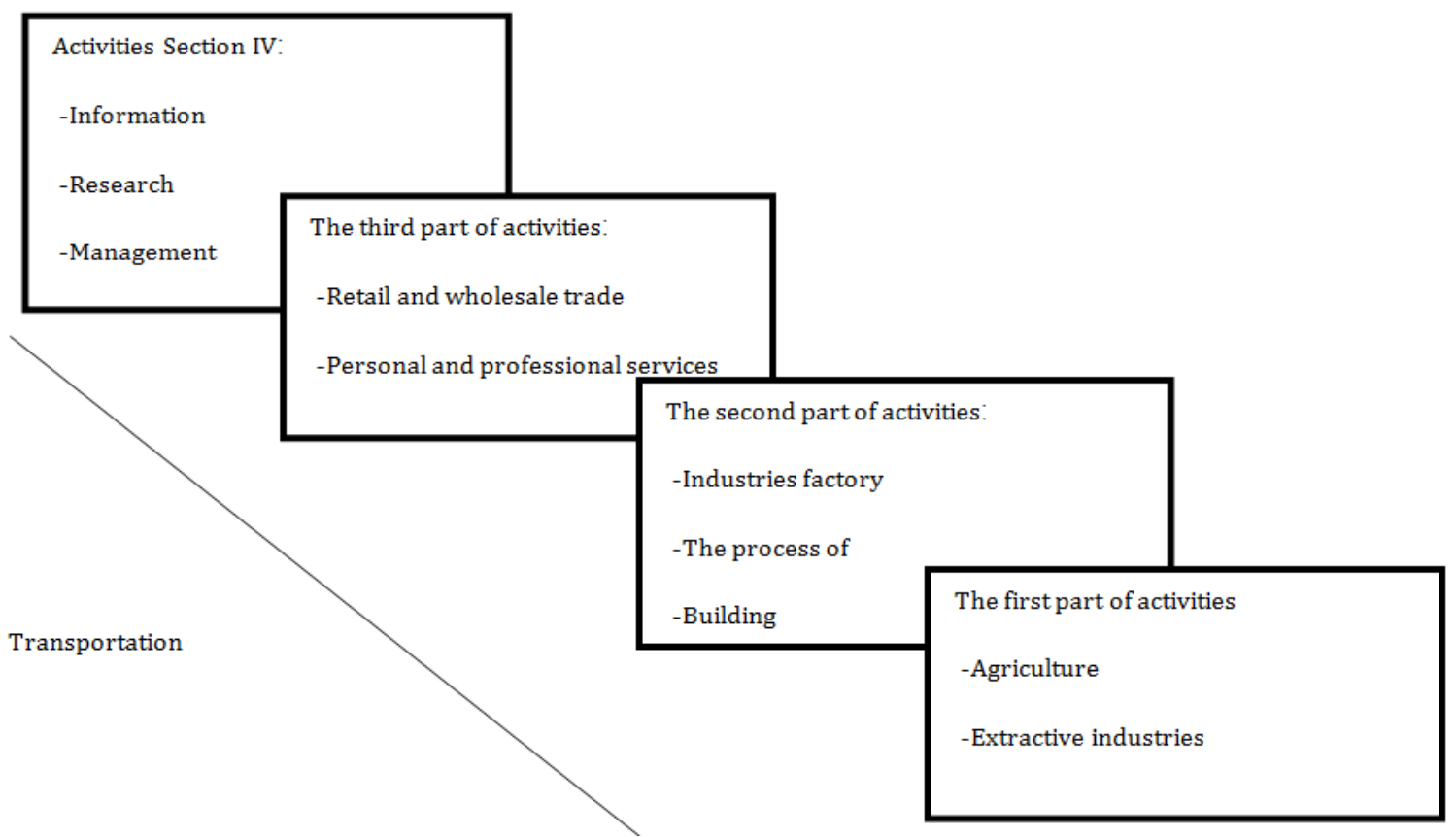

Fig. 1: Transport bed sorts of activities (Getis et al, 2013)

Cycle of economic activity in a wide variety never without the exchange of goods and materials displacement products, telecommunications, and information is not possible; in fact communication and transportation, the relationship between the aforementioned parts. In the global economic system, national and local, transport is the most important variable; no advanced economy without resorting to modern transport network is not able to continue; all traditional societies in developing countries, the benefit from regional and global lines in such a way to remain in geographical isolation. This in turn limits the development of countries and regions.

Economists transport activities including the activities fundamental to economic growth and required for the transformation society to consider. Transport can addition to create facilities for the proper distribution and fast domestic production, context increase production to provide; in the current situation it seems that in any country with any economic situation, production and transportation are interrelated. From the perspective of international transportation can,
Human By combining the basic elements of transport and due to the natural resources in different regions of the globe, various modes of transport to be achieved. Various modes of transportation that each in turn with evolution scientific and technological progress has come, Due to the movement of goods and people from one place to another, the same role with certain characteristics to each other. These characteristics have caused each of them to switch certain economic justification and a total complement each other; types of Activities in the economic geography; the first type of activity, the activity of the second, third and fourth type of activity done in the context of transport (Fig. 1). national effort in achieving makes appropriate production and increase exports succeeded.

Naturally value added of the transportation sector due to significant impact on the supply and demand of their products is the transport sector. As well as other economic sectors, especially agriculture, industry, construction, tourism and foreign trade, also have played a major role in GDP of any problem in the transport sector of the economy is experiencing the problem (Baizaiee, 2005).

Thus we can say that the role of transportation in economic development and create incentives for increased investment is undeniable. Close relationship between transportation volume and level of economic activity there, So that comparisons transportation facilities and services in different countries at different stages of economic development also confirm this relationship (Owen, 1959).

International Union of Railways are abbreviated (UIC) in 1922 after a conference composed of representatives of many governments, with the goal of uniform regulations and conditions of operation of the railway was established. Union headquarters of 
the in France and in Paris. The union is the only business organization that review globally to the needs of rail transportation. And for international cooperation between public and private railway companies have come into existence. Also (UIC), the largest international railway cooperation organization is known that both in terms of number of members and the wide range of activities are considered. Railway Islamic Republic of Iran since 1947 officially became a member of the International Union of Railways. The association was founded in 1922 with 51 members from 29 countries, including Japan and China; gradually joined from all over the world, from the Soviet Union to African countries (UIC). The association has 199 members from five continents in 2012. These members are include 82 active members, 82 associate members and 35 . Members of the association, a total of $1000000 \mathrm{~km}$ network (Iran way com).

In the field of rail transportation research conducted within and outside the country to which they refers.

Haque and Kim (2003) In the Research using the Two estimation method instrumental variables and constant coefficients and random combination, the causal relationship between public investment in transport and communications sector and economic growth using data from 15 developing countries have measured. Results of this study show that the government investment in transport and communications sector cause has been recognize economic growth Granger.

Esterly and Rebelo (1993) have reviewed Continuous communications investment in transport and communications economic growth. Based on some Results of this study, investment in transport and communications, with a correlation coefficient $59 / 0$ to $66 / 0$ have been associated with positive and continuous economic growth.

Another study by Ramirez (2000) has been done as the analysis of structure transport and its effect on economic development in Colombia. This study answers three questions:

The first question is what is the effect of lowering cost of transportation Colombian economy? To respond this question it is estimated societal of savings. The second question is whether the railway is a contributing factor in the twentieth century. Using to be tested the Vector Autoregressive this hypothesis. The third question is whether to expand transport infrastructures can reduce the cost of transportation? To estimate changes the cost of transport we need to have a demand price elasticity estimate, by which social of savings are calculated railway freights.

In a study conducted by Jiwattanakulpaisarn et al. (2010) has been done regarding the development of the transport industry and economic growth in the 48 states of America for the Mdt1997_1984 and sequential compilation. The results of this study shows that external effects and unloading of development of highways in the United States improved labor market situation was different States
And market development and industry boom has created factory.

\section{Research methodology}

This study in the aim of terms of development and in terms of the nature of descriptive and analytical; method this study is documents, according to statistics of the International Union of Railways (UIC) from the years 2008- 2010 are used and then analyzed. Indicators of analysis have been provided by the International Union railways, among these indicators, the five indicator of infrastructure and productivity indicators are among the ten indicators (Table 1).

Selected countries have been selected,from both developed and developing countries, For the role of rail examined as an infrastructure factor affecting the level of development of the countries, These countries, which include (Iran, Australia, Armenia, Azerbaijan, India, Japan, Kazakhstan, Malaysia, Pakistan, Saudi Arabia, Armenia, Canada, Mexico, Austria, Bulgaria, Czech, Lithuania, Poland, Slovenia, Russia, Ukraine, Belgium, Germany, Algeria, Egypt, Congo, Morocco) are more complete data than other member countries in the international Union have available to researchers.

\section{Findings}

\subsection{Data of member countries' railways (UIC) in 2010}

The benefits of rail transport have been used as well as investment in the rail sector by various countries, especially the developed countries due to the transportation industry in the world. For shows Iran's position among member countries International Union of railways (U I C), Twentyseven countries were selected from different continents with different levels of development different from that more detailed information to the rail transport system measured in relation to each of the countries in the index provided by (U I C) in 2010. Among member countries have been selected the International Union railways in 27 countries in order to determine Iran's position and are listed statistics on them (Table 1).

Different countries have been selected by the degree of development, this is because have expressed developed countries a very important infrastructure factor such as road or rail, along with other underlying factors that have a significant role in the development, great importance. And have special attention in parallel with expanding infrastructure, the railways also. As is evident from the charts below such countries in the use of rail is act much stronger than other less developed countries. Among these countries are the region's position in view of the rail transport system in the region to some extent be evaluated. 


\section{Infrastructure of indicators}

\subsection{Distribution of railway lines to population}

The index is represents the lines density of the population of the country. This indicator shows distribution is high the high level of rail lines in the population. Importance of This indicator expresses is the appropriate cover transportation sector that foundation for economic development.

Table 1: Countries of the international union of railways (UIC)

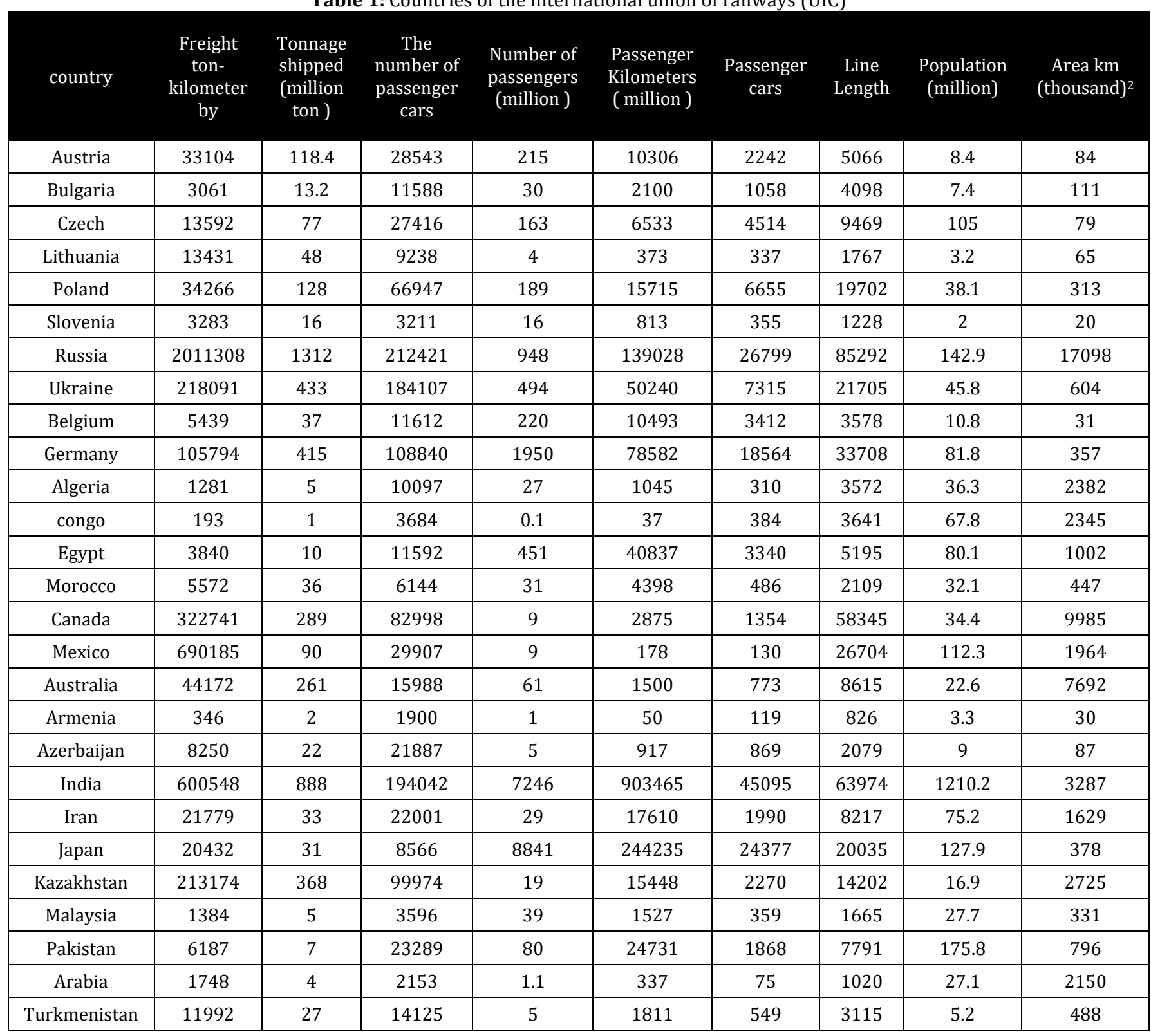

It also reflects the lack of lines length than the population of the country. As can be seen in this indicator the Iran is also much lower than the average level. Iran in the index is allocated with approximately $109 \mathrm{~km}$ of railway lines to the millions No. 19, also Canada is among the countries with approximately 1696 kilometers of rail lines to the million first place and Saudi Arabia is with approximately $107 \mathrm{~km}$ of rail lines to the million people at number 27 (Fig. 2).

\subsection{Distribution of railway to area}

The index represents the congestion at the country level, the high level the index reflects of rail lines than large distribution area of the country. In bottom of graph measures the index the size of the lines, the lack of lines is determined than Breadth of the country. As can be seen in this index Iran is also much lower than the average. Iran in the index with $5 \mathrm{~km}$ long railway to the area thousands of square kilometers is ranking 20's. Czech country with around $119 \mathrm{~km}$ along the lines of a thousand square kilometers is in the first place (Fig. 3).

\subsection{Distribution of passenger cars to population}

This indicator expresses the proportion of passenger cars to the population and shows the frequency of passenger coaches in the population. 
High level of this indicator shows large distributed passenger cars relative to population. Also high level it is of in the distribution of passenger by train plays an important role. Distribution passenger car in proportion in the population was lower than average. Iran ranks its 20 th on the index with 26 car relative to per million, Also, Belgium with 316 wagons and Mexico with 1 wagon to per million were respectively in the first rank late (Fig. 4).

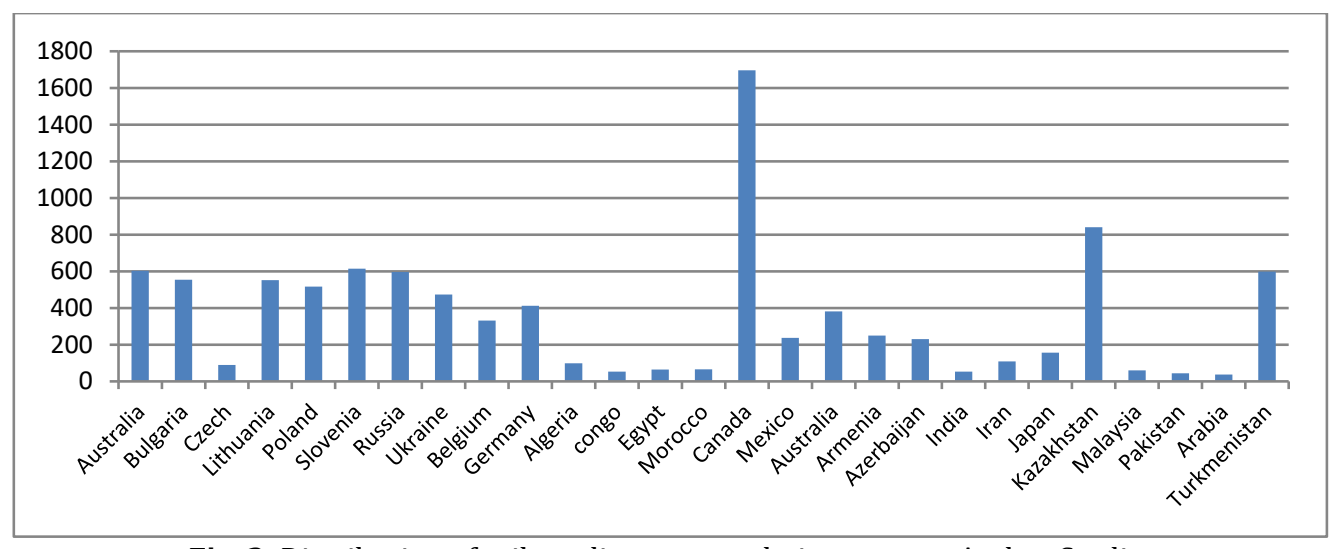

Fig. 2: Distribution of railway lines to population, source: Author Studies

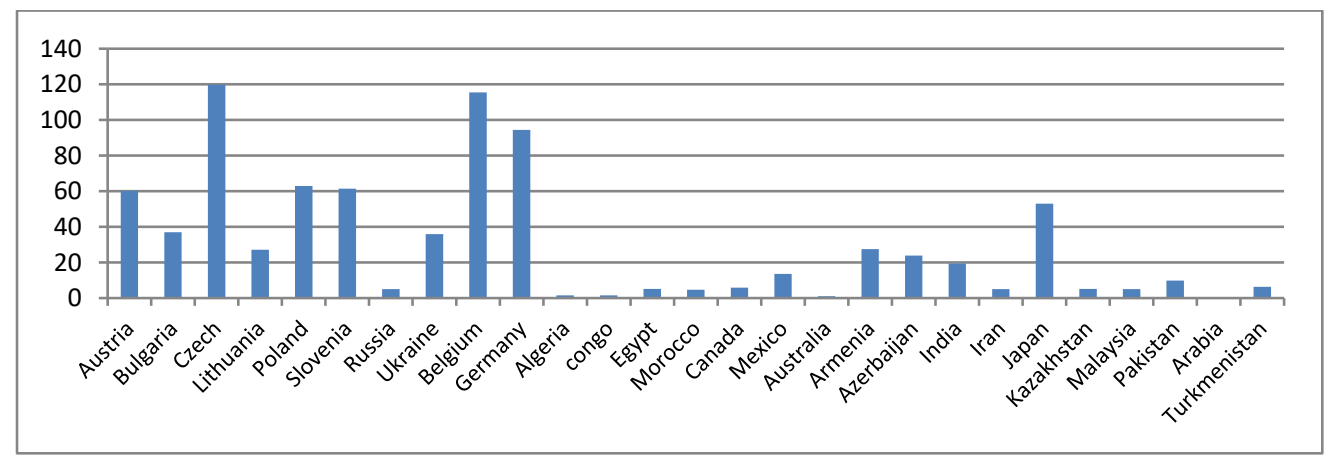

Fig. 3: Distribution of railway to area, source: Author Studies

\subsection{Distribution of passenger cars to length rail}

The ratio is shown that the frequency of passenger carriages length lines of the railways of passenger cars. And the higher the level of these index shows that relative to the rail is high of the distribution of passenger cars and is done optimal utilization of railway lines (Fig. 5). In this index, we can see that is less passenger cars for transport to length rail network. Iran index was account ranked $14^{\text {th }}$ with 0.24 Passenger cars in length of railway. As well as Japan and Mexico respectively 1.2 and 0.005 in the selected countries are ranked first and the last.

\subsection{Distribution of freight car to length railways}

The ratio of freight car in length of lines indicates the frequency of freight cars to the railways. This index shows the higher the level of that relative the freight car to rail is more distributed. Iran in this index is lower than the average level and has been with around 3 freight car than to $\mathrm{km}$ long railway in place 16. Also has been Azerbaijan with about 10.5 freight cars to kilometers long lines to the first rank and Japan with around 0.4 freight cars to kilometers long lines of the last rank (Fig. 6).

\subsection{Productivity of indicators}

Using the infrastructure can be calibrated various measures in from which they referred to as an indicator of Efficiency.

\subsection{Efficiency of rail lines}

Productivity index represents the efficiency in the use of rail lines of in the shape of passenger kilometers and ton-kilometer cargo is transported. The high this indicator shows per unit railway is created how much transported passenger and cargo. As the can be seen from the charts, Iran of the index with around 17,600 km person passenger and cargo ton-kilometer is in position 8. India, with around 903 500 passenger kilometers and ton-kilometer freight carried has ranked first in the index. And the Congo with around $37 \mathrm{~km}$ of passengers carried and ton kilometer cargo Rating 27 (Fig. 7).

\subsection{Efficiency of freight cars}

This index reflects the performance of freight cars shows that on average each freight car what extent has tons of cargo. Whatever it is amount more is, indicating that the efficiency of freight cars. Moreover, the transit cargo, cargo outgoing and incoming and internal cargo and also location is suitable transit and export cargo this index will have a higher rank. 
Efficiency of Freight Wagons in our country is lower than average and about 0.0015 million tons of cargo to freight car was shipped with the number 18 to be allocated. As well as Australia with around
0.016 and Congo with around 0.0003 million tons of cargo were transported to freight car are located, respectively, in the first place and 27 (Fig. 8).

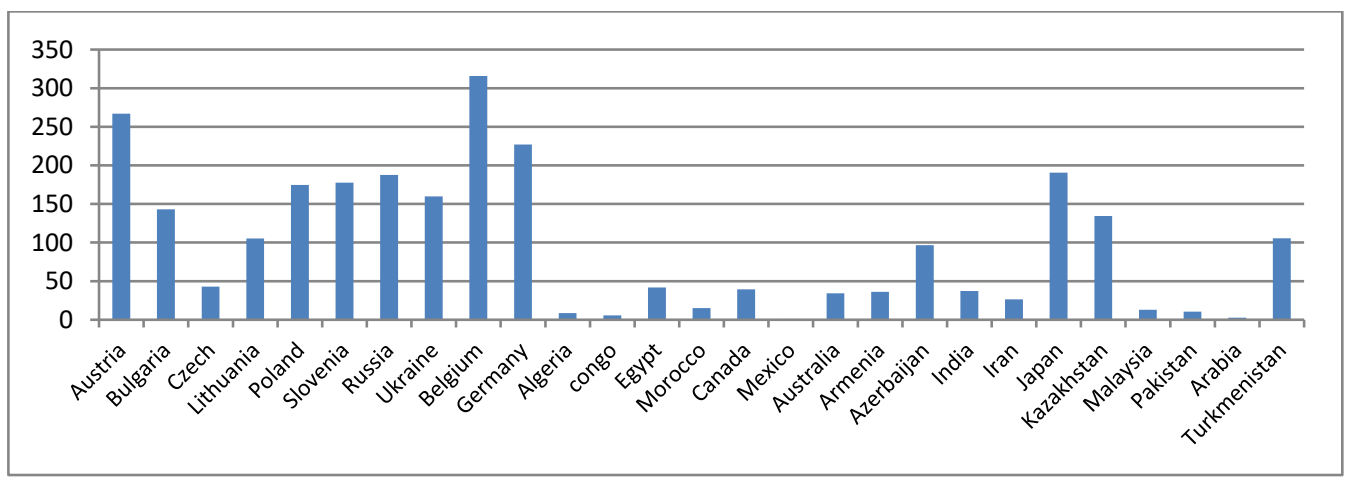

Fig. 4: Distribution of passenger cars population, source: Author Studies

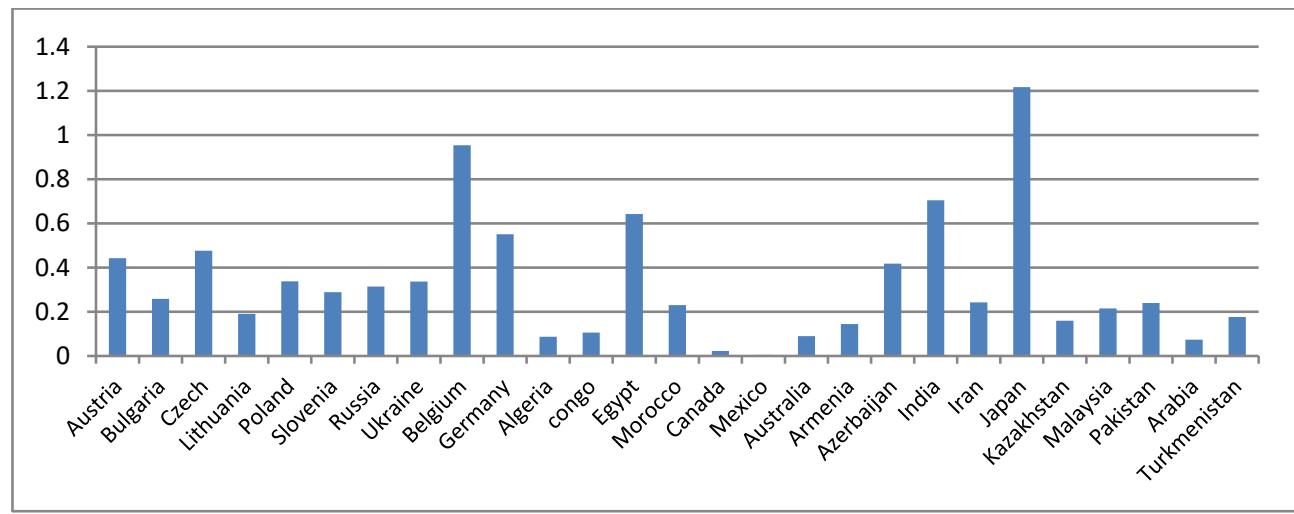

Fig. 5: Distribution passenger cars to length railways, Source: Author Studies

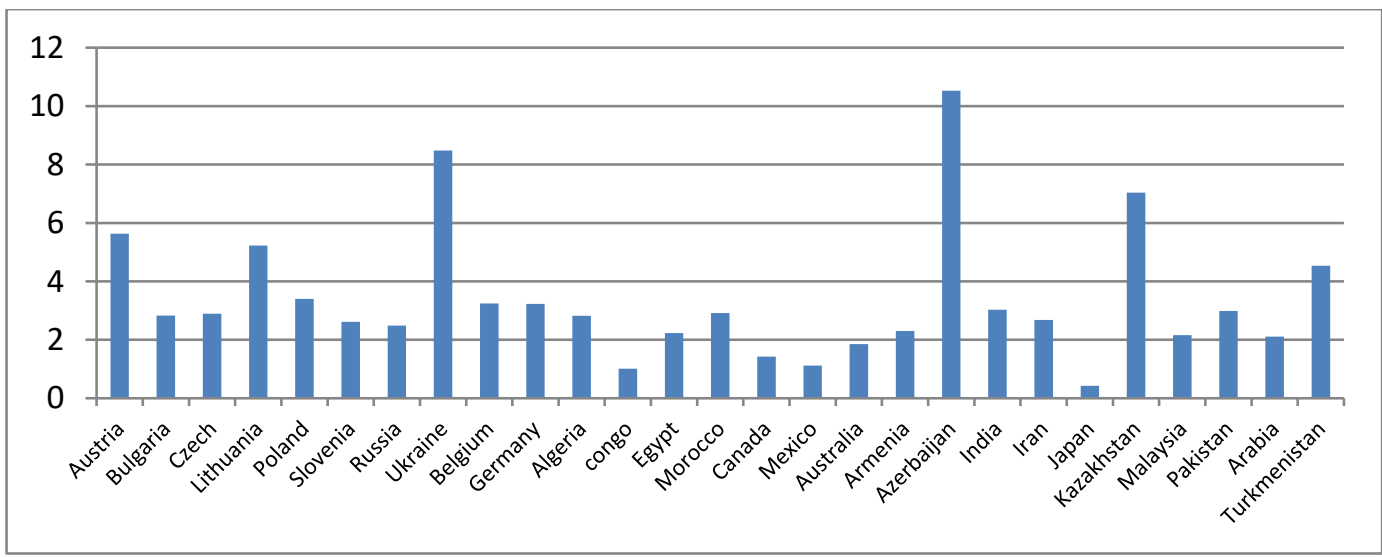

Fig. 6: Distribution of freight car to length railways, Source: Author Studies

\subsection{Distribution ton-kilometer of long lines}

The index reflects the performance of the freight cars, which shows the average freight cars of the tonkilometer, is how much has carried cargo. Whatever that number is larger, indicating that the efficiency of railway freight cars more. As well as transit cargo, cargo exported and imported and domestic cargo over long distances further particularly, this index will be a better place. The affect country's position on this indicator on transit and export loads. Iran on this indicator, with about 2.7 tons of cargo carried on length of railway lines, ranked 14 and is lower placed than average. Also, Mexico in the index with approximately $26 \mathrm{~km}$ of Congo with about 0.05 tons $\mathrm{km}$, cargo carried on to the length of railway lines, are respectively, in the first place and 27 (Fig. 9).

\subsection{Distribute the load the rail}

Distribution index cargo carried by rail, measures the amount cargo carried to the length of the lines.The high index represents the optimal use of rail of cargo services. In this index, the country with about 0.004 million tons cargo carried to the length of the lines, productivity is less than average and ranking 17 th in the world.

And if the country's rail fleet in the index measure with countries in the region are placed, after Kazakhstan, Azerbaijan and Turkmenistan. 
Australia has about 0.03 and the Congo with about 0.0003 million tons cargo carried to the length railway lines are located, respectively in the first and 27 rank (Hanging Fig. 10).

\subsection{Distribution of the passenger $\mathrm{km}$ to population}

Iran's rank in the index 8 is with approximately 2.2 million passenger $\mathrm{km}$, in fact, the number of passengers, the distance they have traveled than length railway lines, close to amount average. As a result, long-distance travel by train is used by people. And to improve the quality and speed of trains in the country can be achieved superior status in the index. Also, in India, with about 14.2 million passenger $\mathrm{km}$ and Mexico with about 0.007 million passenger kilometers, compared to the length of the lines are, respectively in the first and 27 ranks (Fig. 11).

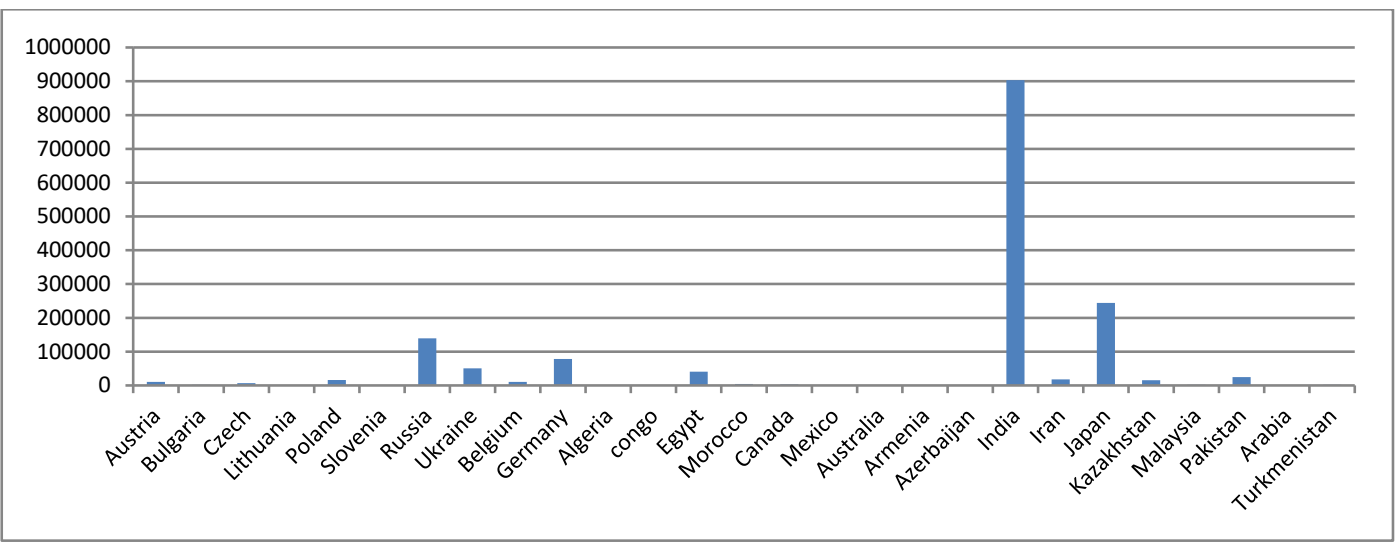

Fig. 7: Efficiency rail lines, source: Author Studies

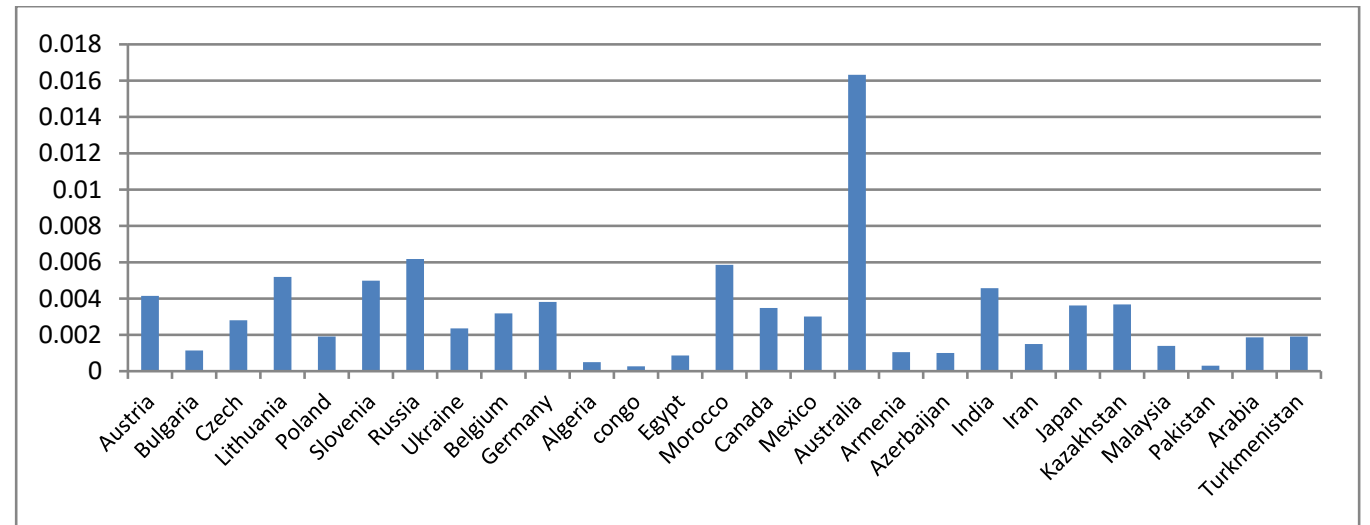

Fig. 8: Efficiency freight cars, Source: Author Studies

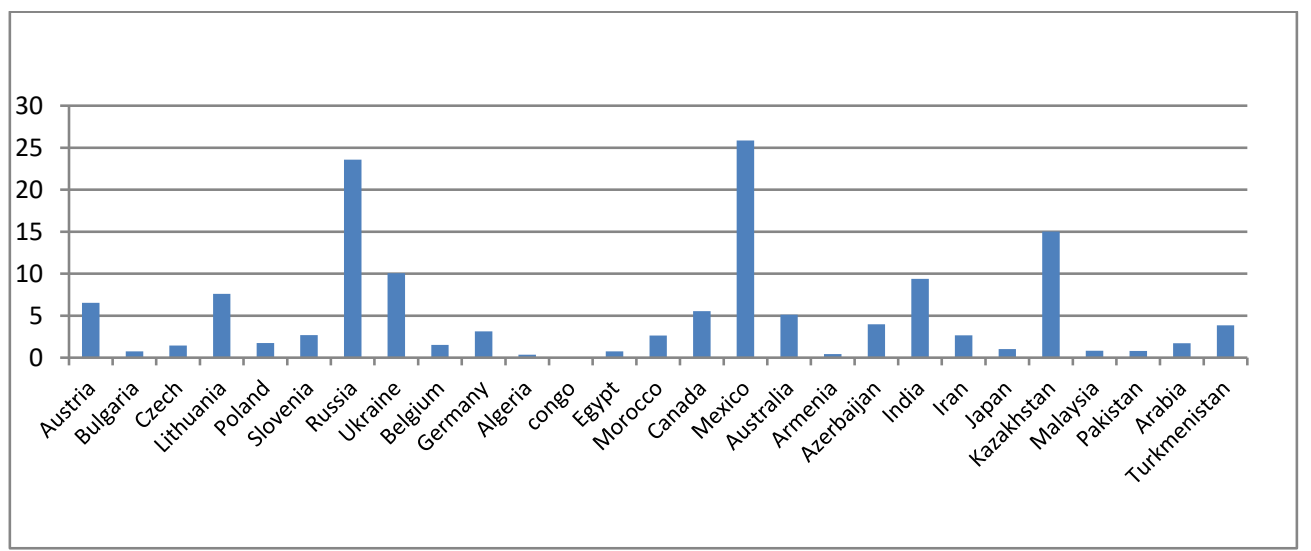

Fig. 9: Distribution of ton-kilometer-long lines, source: Author Studies

\subsection{Efficiency passenger $\mathrm{km}$ to Passenger wagon}

As is graph shows, the country with approximately 8.9 million passenger kilometers in the index, compared to passenger wagon accounted
Rank 6 and will be higher than average. It should be noted India with 20 million and the Congo with about 0.01 million passenger $\mathrm{km}$ compared to passenger wagon are allocated the first and last respectively rank (Fig. 12). 


\subsection{Efficiency of Passenger carriages}

This indicator indicates is the number of passengers compared to passenger coaches. In this index, the country is far with amount average. And approximately 0.15 million people each passenger wagon is ranked 19 th.

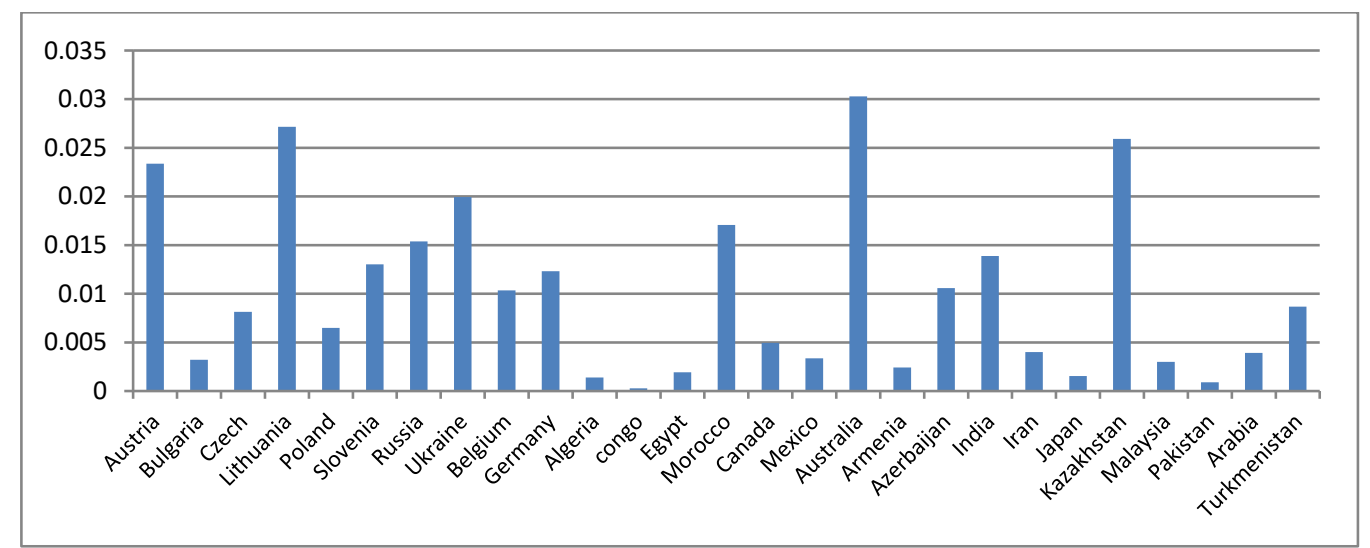

Fig. 10: Distribute the load the rail, source: Author Studies

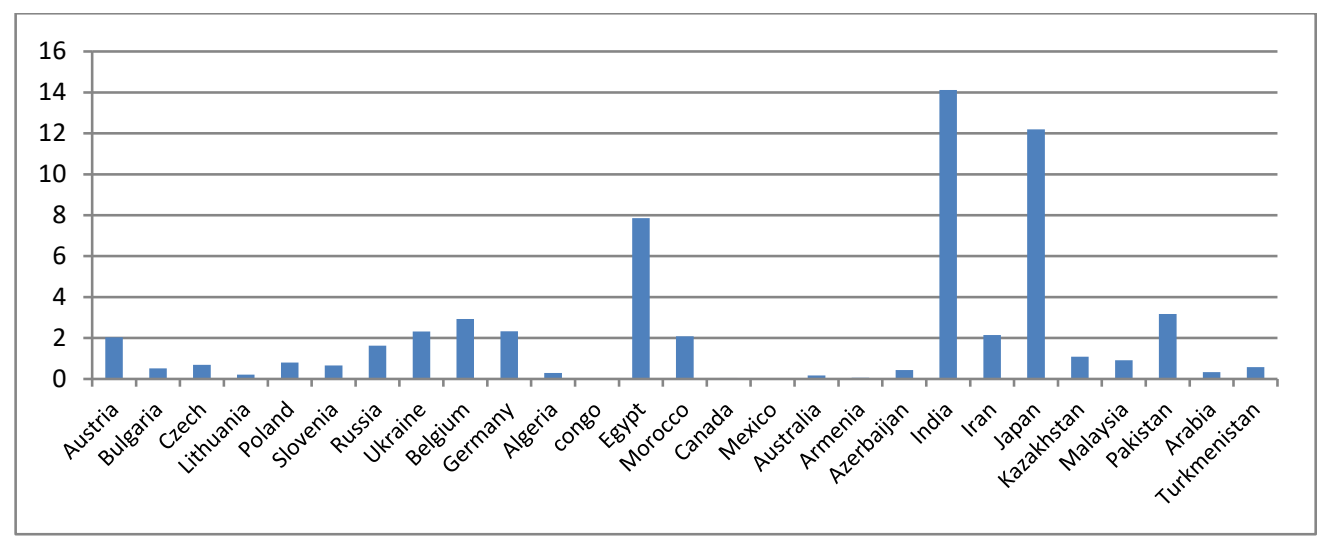

Fig. 11: Distribution of the passenger km to population, source: Author Studies

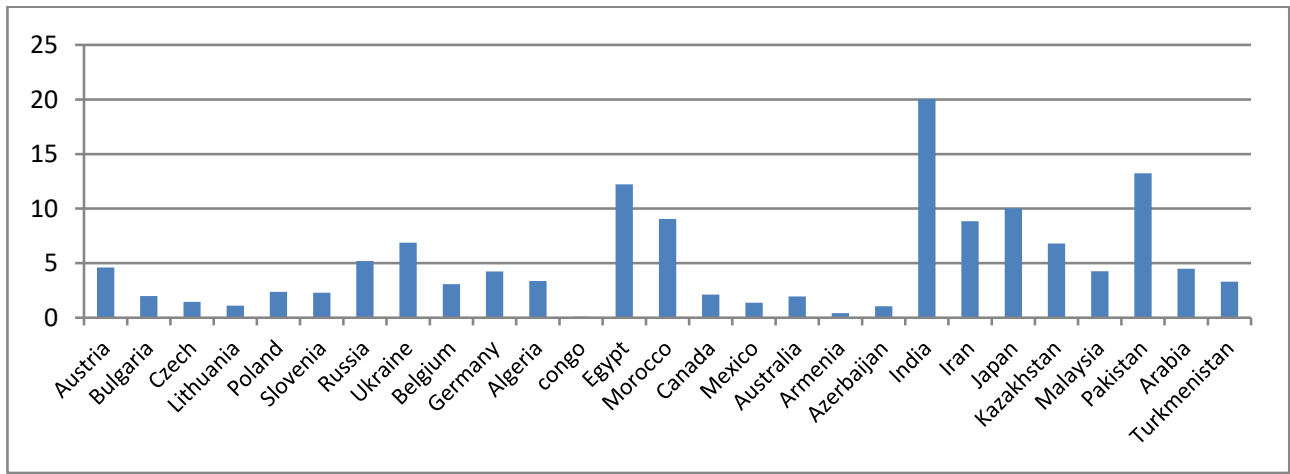

Fig. 12: Efficiency passenger km to Passenger wagon, source: Author Studies

In general, the number of passengers over long distances and short of the number of passenger cars is much less. Japan, with approximately 0.4 million passengers and Congo with approximately 0.0003 million passengers compared to each passenger wagon, respectively, in the first place and last place (Fig. 13).

\subsection{Distribution passenger to the population}

This indicator is the attention of passengers to rail transport system. Whatever amount this indicator the greater shows importance of train travel as a safe means of transportation. Unfortunately, in this index, Iran of about 0.4 million passengers to the population to allocated number 22 and the position is much lower than average. As well as among developing and developed countries there is much difference in this index. As can be seen, with approximately 69.2 million passengers in Japan and the Congo with approximately 0.002 million passengers, than to the population, respectively ranked first and final are allocated (Fig. 14).

\subsection{Distribution passengers to the railway lines}

Whatever the index the larger number display indicates the desirability and importance are traveling by rail in the country. As the graph is the result of a lack of attention passengers in the index 
of the rail system is evident. In this index, is located the country with approximately 0.004 million passengers compared to the railway lines on rank 18th. Also Japan has about 0.45 million people and
Congo with approximately 0.00003 million passengers are compared to length railway lines, respectively, ranking first and last (Fig. 15).

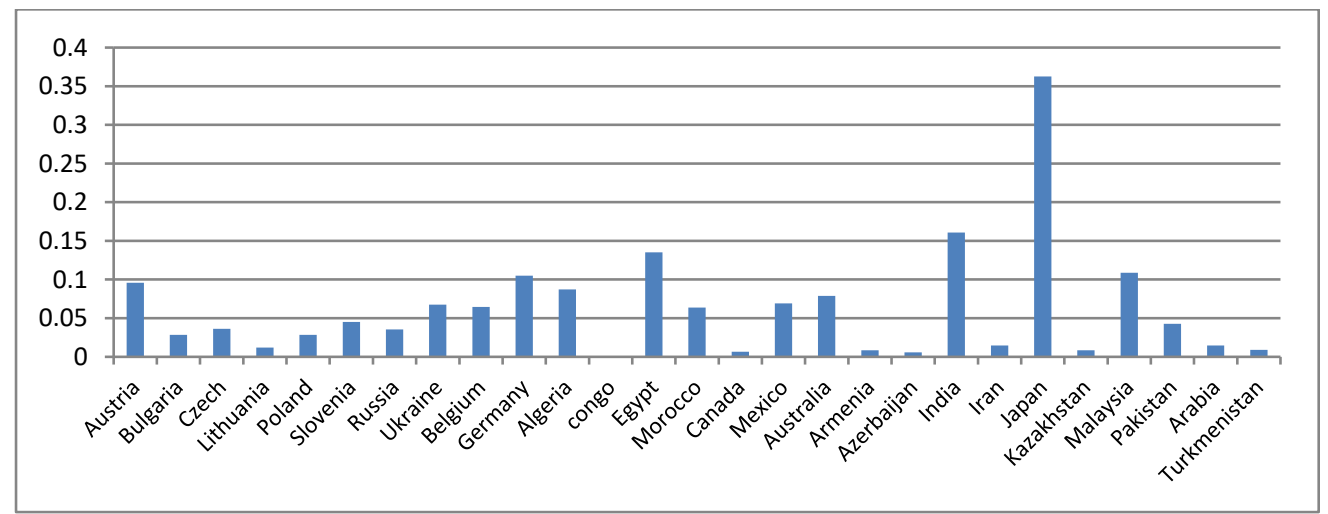

Fig. 13: Efficiency of Passenger carriages, source: Author Studies

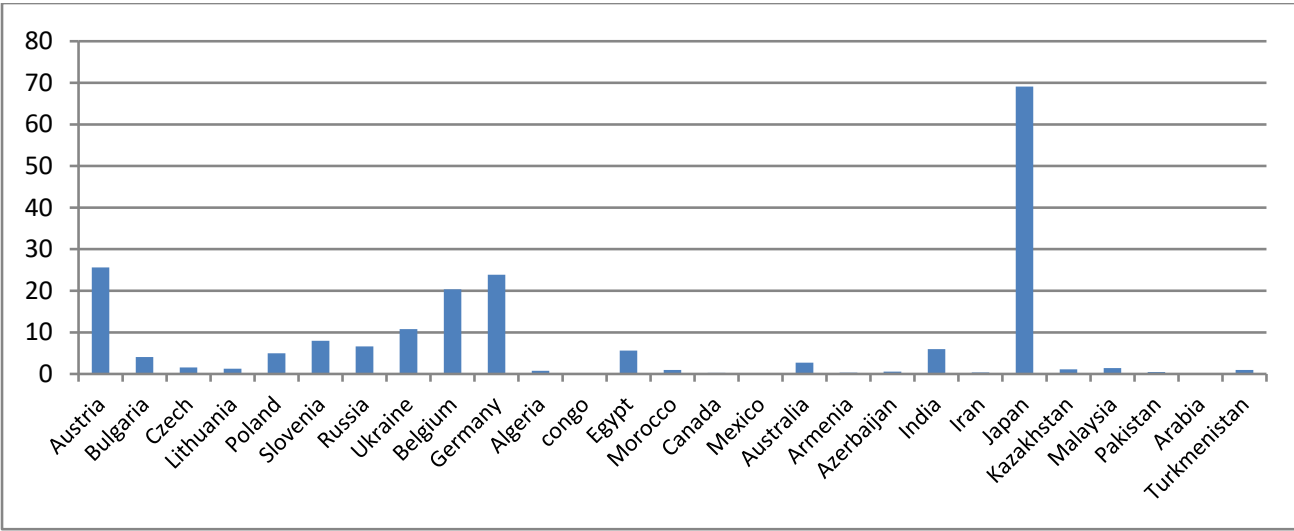

Fig. 14: Distribution Passenger to the population, source: Author Studies

\subsection{Distribution of the passenger $\mathrm{km}$ to population}

This indicator also suggests the desirability and importance of are traveling by rail in the country. Iran's position on this indicator was higher than the average and rank 8 with about 234 million passenger $\mathrm{km}$ to the population of the country. This chart revealed that that the number of passengers who traveled by train are further than other countries. In general, over long distances train travelers are more willing to use. Japan, with approximately 2910 million passenger $\mathrm{km}$ and Congo with approximately 0.6 million passengers $\mathrm{km}$, compared to population, respectively, ranked first and last place (Fig. 16).

\section{Discussion and conclusion}

Today we can see in the world by the use of new signs systems and communications facilitate the commuter trains, speed and as well as safety and dare we claim the goes rail transport industry's technology high-speed Postmodernism. This is while our facilities in the rail transport sector is not the extent and size global standards (especially for the high speed train) and Among the obstacles and deficiencies in our country's rail industry can be known without the use of advanced technology in the transportation industry. After studying the rail industry and compare it with several countries the results we have obtained expresses this matter that, in infrastructure indexes are weak such as: distribution of railway to population, distribution of railway to area, distribution of passenger cars and freight car to population, distribution of passenger cars and freight car to length railways.

As a result should be more passenger cars with quality as well as high-speed trains for trips with longer route, we enter the rail fleet, With increasing lines at the station, the traffic created to reduce train entering a station and find the main grandstand control fleet upgrade rail systems, in cargo and passenger us. Countries such as Japan, India, Russia and Germany using equipped fleet and of high-speed trains has very strong indicator. It should be noted that in index per passenger kilometer relative to wagons and crowds that are indicators of efficiency, long-distance travel by train will be welcomed by the people.

Also in productivity indicators such as freight and passenger also lower than average compared between countries and the situation has not been located. Also in transit fits the strategic requirements of the country have not and compared to regional countries, including Kazakhstan, Azerbaijan and 
Turkmenistan that we are weaker than them. It should be noted, Iran is at a crossroads of rail transit world that unique situation puts at the disposal of transportation and transit. The amount of transit has increased in recent years in the country, but the share of rail transit is much less than the share of road transport and this indicates a lack of railway network coverage in sensitive and important areas as well as is weakness of the existing fleet and worn out fleet. Lack of rail equipment and improper coverage will cause transit opportunities, as a very important source of income in today's world have been placed at the disposal of countries in the region. In addition to the special position of Iran in the region compared to other countries (Fig. 17), the premier's position of transit, safety is very high compared to other countries in the region and access to open sea, the other capabilities of the country.

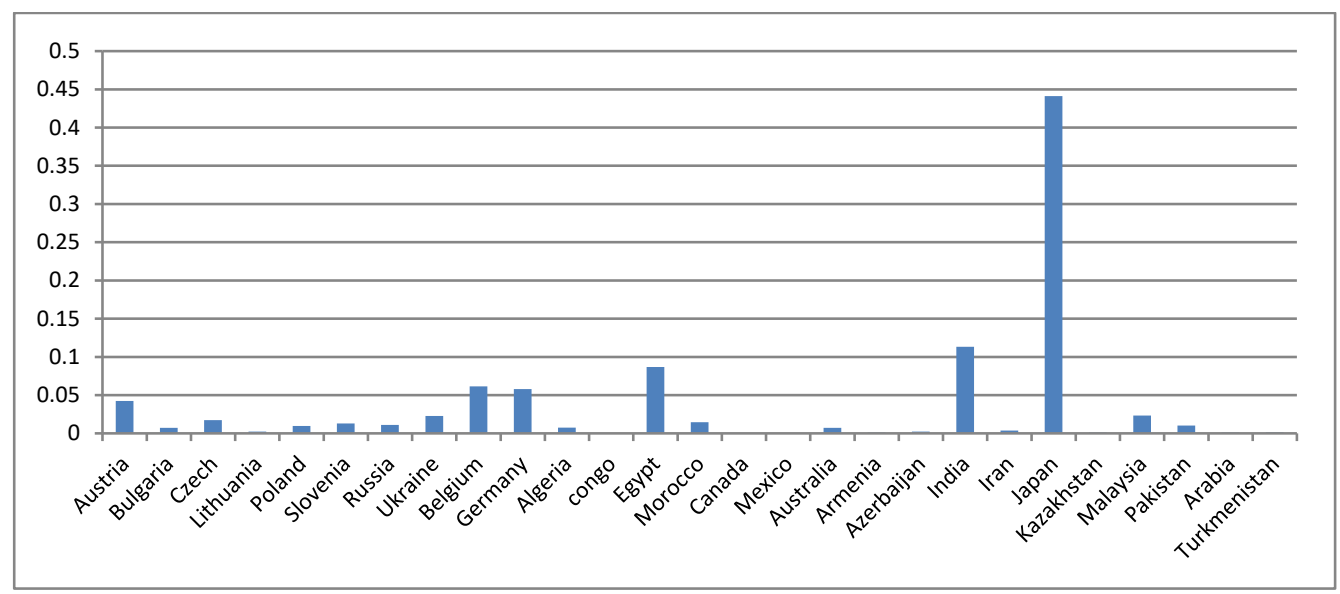

Fig. 15: Distribution passengers to the railway lines, source: Author Studies

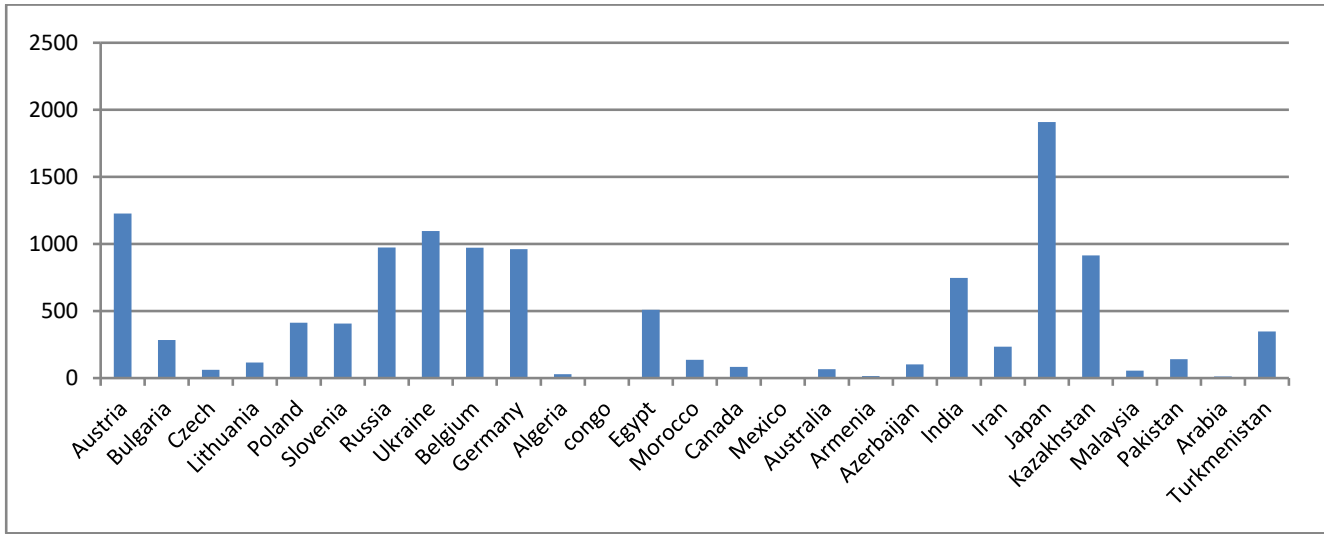

Fig. 16: Distribution of the passenger km to population, source: Author Studies

Therefore, it is important that we have many indicators listed, much stronger act than other regional countries, While Unfortunately Azerbaijan, Kazakhstan, Turkmenistan, Pakistan, that situation is similar to us and can even rival for Iran, we have allocated a lower position. Also by connect only ocean port country to rail network, the shortest route will be formed in the country for transit goods Central Asian countries. And rival Chabhr that Pakistani port of Karachi port, due to shorter route and safer Chabahar, less attention will be placed regional transit markets. The following suggestions have been noted:

- Increase the fleet and rail network, particularly the use of trains Extremist

- Transnational approach to the rail network connection strategic locations on the rail network and rail network connecting the network to neighboring countries and the proper marketing
- Comment combined transport system and a special focus on safe and low-cost rail transport system

- Facilitate customs and transit discounts for transit and export goods and transport container

- Establishment of diplomatic relations with countries in the region and strives to increase the new markets for its transit

- Increased budget in the rail transport sector according Iran opportunities in the field

- Determining the rate of transport of goods and passengers and increasing the share of passenger and cargo movement in the rail sector

- Reduce the amount of tariffs for railway companies for the use of railway lines

- Reduce the price of cargo by rail companies, thus will be decreasing the transportation by truck, and the load transfer from road to rail.

- The private sector participation in areas where development is economically feasible 
- Create areas that do not make economic sense just to land justice are shaped by the public sector
- The use of specialists and the elimination of inefficient and non-specialized forces from the rail.

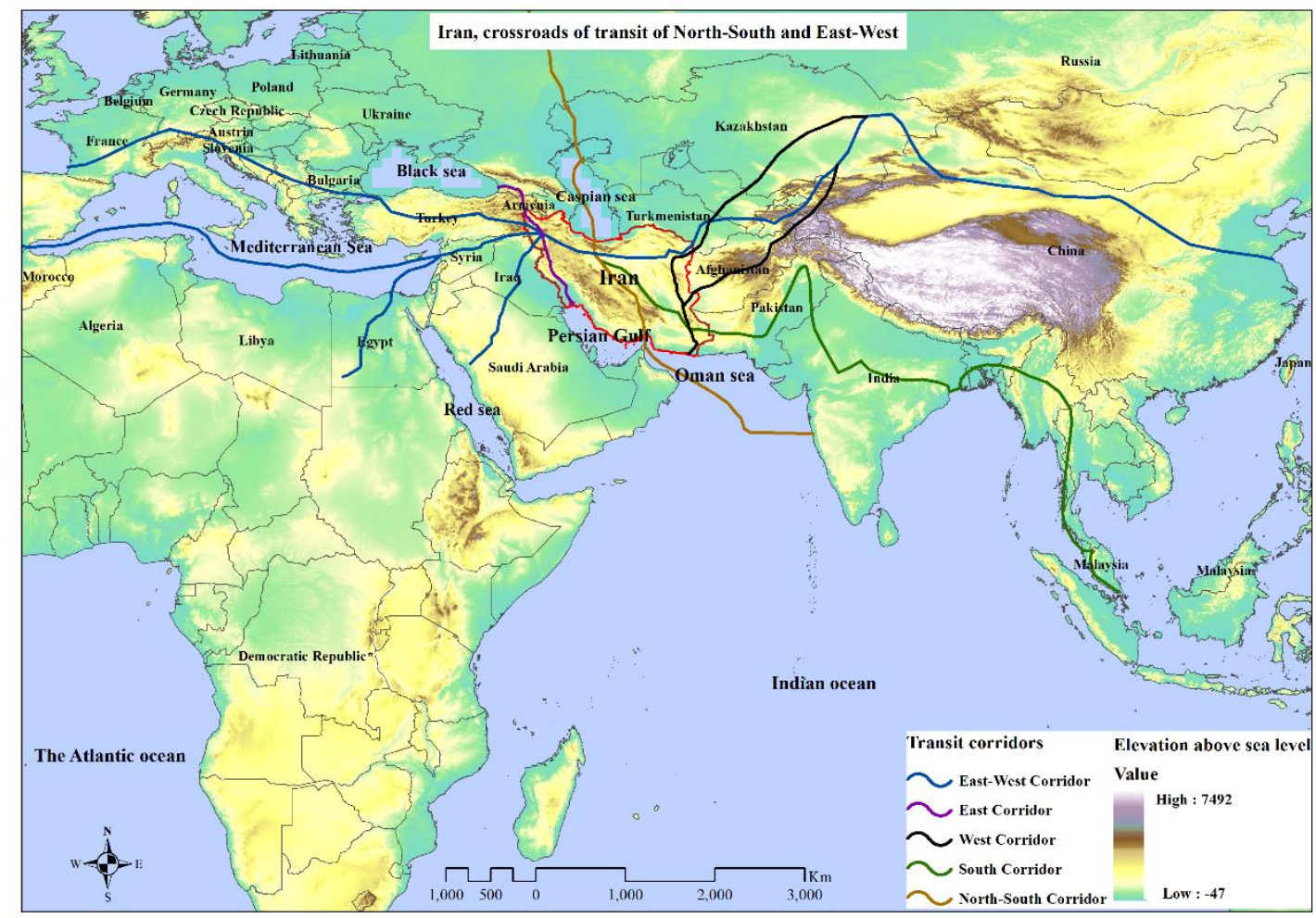

Fig. 17: Position of transit in Iran, drawing: author

\section{References}

Baizaiee SE (2005). Factors determining the value added in transportation sector and GDP in the Islamic republic of Iran. Journal of Transportation Research, 1(2): 65-77. Available online at: http://en.journals.sid.ir/ViewPaper.aspx?ID=286 62.

Easterly W and Rebelo S (1993). Fiscal policy and economic growth. Journal of Monetary Economics, 32(3): 417-458.

Getis A, Bjelland M, and Getis Y (2013). Introduction to geography. 14th Edition, McGraw-Hill Education, New Yourk, USA.

Haque ME and Kim DH (2003). Public investment in transportation and communication and growth: a dynamic panel approach. University of Manchester, School of Economic Studies.

Jiwattanakulpaisarn P, Noland RB and Graham DJ (2010). Causal linkages between highways and sector-level employment. Transportation Research Part A: Policy and Practice, 44(4): 265280.

Owen W (1959). Transportation and economic development. The American Economic Review, 49(2): 179-187.

Ramirez M (2000). Railroads and Colombia economy. In Bogota: Banco de la República, Mimeo, paper presented at the 2000 Econometric Society World Congress. 